\title{
Influence of functional abilities on the quality of refereeing in handball
}

\author{
Authors' Contribution: \\ A Study Design \\ B Data Collection \\ C Statistical Analysis \\ D Data Interpretation \\ E Manuscript Preparation \\ F Literature Search \\ G Funds Collection
}

\author{
Ivan Belcic ${ }^{1}$ ABCDEF, Lana Ruzic ${ }^{2}$ AD , Alen Marosevic ${ }^{3 B F}$ \\ ${ }^{1}$ Department of Kinesiology of Sports, Faculty of Kinesiology, \\ University of Zagreb, Zagreb, Croatia \\ 2 Department of Kinesiological Anthropology and Methodology, Faculty of Kinesiology, \\ University of Zagreb, Zagreb, Croatia \\ ${ }^{3}$ Women National Handball Team U19, Croatian Handball Federation, Zagreb, Croatia
}

\section{abstract}

Background: Several factors contributed to the evolution of handball, and one of the most important changes for faster, more dynamic and aggressive game is the change of rules which increase physical demands of players and especially referees. The aim of this study is to determine whether functional abilities have an influence on the quality of refereeing.

Material and methods: 31 subjects were involved in the research, all of them top-level referees with an average age of $34.66 \pm 6.44$, height $184.02 \pm 5.87 \mathrm{~cm}$ and body mass $91.14 \pm 10.61 \mathrm{~kg}$. Testing was divided into two parts: the first part was spiroergometric progressive test on a treadmill to diagnose functional abilities, and the second part was the official handball matches.

Results: Results show an average relative maximum oxygen uptake of $45.35 \pm 6.12 \mathrm{ml} / \mathrm{min} / \mathrm{kg}$. No statistically significant correlation was found between better functional abilities of handball referees and a better quality of refereeing.

Conclusions: Referees have a lower anaerobic capacity, which could lead to errors in their judgment during the highest physiological loads in a match. Referees are a homogeneous group due to elimination criteria on tests at official seminars. If there were no elimination criteria, there would be greater variability among referees, and it would be possible to confirm the hypothesis that better functional abilities would lead to a better quality of refereeing.

Key words: team handball, physical fitness, spiroergometric test, maximum oxygen uptake, referee.

\section{article details}

Article statistics: Word count: 4,302; Tables: 3; Figures: 3; References: 31

Received: May 2020; Accepted: June 2020; Published: September 2020

Full-text PDF: http://www.balticsportscience.com

Copyright ๑ Gdansk University of Physical Education and Sport, Poland

Indexation: Celdes, Clarivate Analytics Emerging Sources Citation Index (ESCI), CNKI Scholar (China National Knowledge Infrastructure), CNPIEC, De Gruyter - IBR (International Bibliography of Reviews of Scholarly Literature in the Humanities and Social Sciences), De Gruyter - IBZ (International Bibliography of Periodical Literature in the Humanities and Social Sciences), DOAJ, EBSCO - Central \& Eastern European Academic Source, EBSCO - SPORTDiscus, EBSCO Discovery Service, Google Scholar, Index Copernicus, J-Gate, Naviga (Softweco, Primo Central (ExLibris), ProQuest - Family Health, ProQuest - Health \& Medical Complete, ProQuest - Illustrata: Health Sciences, ProQuest - Nursing \& Allied Health Source, Summon (Serials Solutions/ProQuest, TDOne (TDNet), Ulrich's Periodicals Directory/ulrichsweb, WorldCat (OCLC)

Funding: This research received no specific grant from any funding agency in the public, commercial, or not-for-profit sectors. Authors have declared that no competing interest exists.

Ivan Belcic, Horvacanski zavoj 15, 10000 Zagreb, Croatia; tel. +385 / 95904 - 67 32; e-mail: ivan.belcic@kif.hr This is an open access article distributed under the terms of the Creative Commons Attribution-Non-Commercial-NoDerivatives 4.0 International (https://creativecommons.org/licenses/by-nc-nd/4.0/), which permits use, distribution, and reproduction in any medium, provided the original work is properly cited, the use is non-commercial and is otherwise in compliance with the license. 


\section{INTRODUCTION}

Handball is an increasingly popular sport that has been developing fast, especially in the last eight years at all major competitions, such as the European and World Championships and the Olympic Games [1]. This refers to the growing dynamics of play, aggression and speed of the game - both in defence and attack. Several factors contributed to the development of handball in this direction, and one of the most important changes in the rules is quick restart of the game after a team scores a goal and also a change related to the passive game [2, 3, 4]. After these changes in handball, the time between the defence phase and the attack phase was significantly reduced, so the game became more dynamic and demanding $[5,6]$ both for players and for referees. Another direct consequence of changing the rules of the game is the reduced first part of the attack, which has led to more dynamic and faster games and to more sophisticated tactics in the game [1]. Accordingly, the rule of quick restart of the game after team scores a goal has contributed to the larger physical demands for players [3] as well as for referees whose physiological load during the game may be higher than the physiological load of players during the match [7].

Parameters which play a significant role in selection of handball players include anthropometric characteristics (knowledge of dominant characteristics for selection in handball), functional abilities of organs and organic systems (aerobic and anaerobic capacity), motor skills, social characteristics as well as cognitive and conative characteristics. That is why the aim of this paper was to check whether the functional abilities of handball referees have an impact on their quality of refereeing. New trends in technical, tactical and physical development of handball game require referees to have highly developed functional abilities. It is the referees' duty to be as close as possible to the game and to notice and sanction the violation of the rules in team sports. Moreover, the success of refereeing and making good decisions in these sports is closely linked to the ability to follow physical and physiological demands during the match $[8,9$, $10,11,12]$.

Physical demands of referees during the game are dictated by athletes, and athletes are on average between 10 and 15 years younger than the referees [13]. For this reason, referees must maintain their functional abilities at an adequate level, especially knowing that functional abilities are reducing in their quality over time. Unlike earlier, when success was mostly conceived in the players' technical preparedness, today's modern handball requires players to have a higher level of physical fitness [14]. Although lower league referees can compensate for a lack of physical preparation with their experience, at an international level and higher leagues this is not possible any more [15]. Bearing this in mind, referees must be physically ready to follow the flow of the game and to be as close as possible to field activities [9, 16, 17, 18, 19, 20]. Good positioning from referees is only possible if they are mobile and physically fit for physical requirements of sport. Also very important for referees is to be able to maintain mental concentration and make good and correct decisions about field situations in a fraction of a second [9].

By carefully studying the available literature concerning referees in several types of team sports, with a particular emphasis on handball referees, it can be concluded that refereeing is a demanding long-lasting and highly complex process of improvement in decision-making skills. Quality refereeing cannot be trained, but understandably, it is a logical sequence of gaining experience 
through years of refereeing with a large number of matches and, along with those matches, a large number of non-specific situations in which referees find themselves, stereotypically learn and later apply that knowledge. A referee in any team sport, especially in handball, must be very fit to follow physical requirements during the match, especially those of submaximal and maximal loads. Referees must maintain their functional abilities with carefully planned and programmed trainings. It is very important that the referee have a very well developed aerobic capacity for undisturbed and constant movement during the match. Also, it is important to have developed anaerobic capacity as well for very frequent anaerobic activities of the sprint type, which are the result of a quick restart of the game after changing the rules of handball. It is very important for high-quality positioning, undisturbed following of all technical-tactical elements in the game that require rapid movement, especially counterattack. With individual work for improving aerobic capacity, referees should pay more attention to improve their anaerobic ability to keep track of a large number of repeated high intensity activities. Such a referee will have the slightest influence on the outcome or the flow of the match, and with its appearance, it will lead the players to achieve their maximum abilities in equal field conditions. Handball referees were the least represented subject of scientific research of the team sports referees in the literature, and they have very limited available databases, so this research will contribute to handball as a sport, especially to handball referees.

The aim of this study is to determine whether functional abilities have an influence on the quality of refereeing, with a tested hypothesis if there is statistically significant correlation between better functional abilities and a better quality of refereeing.

\section{MATERIAL AND METHODS}

\section{ETHICS COMMITTEE APPROVAL}

This study has been approved by the ethics committee of the Faculty of Kinesiology, University of Zagreb.

\section{SUBJECTS}

For this study a total of 31 subjects were tested. All of them were handball referees from the Premier Croatian Handball League. Referees in handball are always in pairs and like this they have also attended all of the tests for this research (one referee got injured before the spiroergometric test, so he is excluded from the results). Referees on the list of Premier league handball in Croatia are selected every year according to grades during the previous season, and the list is confirmed by the professional committee of the Croatian Handball Referees Association. Referees' average age was 34.66 \pm 6.44 years, height $184.02 \pm 5.87$ centimetres and body mass $91.14 \pm 10.61$ kilograms.

\section{PROCEDURE}

Due to maximal and sub-maximal efforts during testing of examinees, each subject needed to provide a medical certificate which allowed them to undergo all the testing for this research. Examinees provided a signed statement of their willingness to proceed testing. Testing was performed in two parts and different venues in the second part of testing. Firstly, testing was performed at 
the Faculty of Kinesiology of the University of Zagreb in the Diagnostic Center. Subjects followed the same protocol of warm-up which lasted for 20 minutes (dynamic stretching, basic running and running with change of direction, intensity and speed, static stretching). After warming up, examinees took a spiroergometric progressive load test on the treadmill to test their functional abilities. The spiroergometric progressive load test on the treadmill is always supervised by experts who conduct the protocol along with a medical doctor. The test was performed in a closed and ventilated room, with controlled constant microclimatic conditions $\left(18-21^{\circ} \mathrm{C}\right)$. The computer with the accompanying device displayed the examinee's data numerically and graphically during realtime testing on a computer screen. For safety testing and data reliability, two sets of telemetric heart rate monitoring systems (Polar RS 400) had been attached to the subject before the testing. During the test, the subjects breathed with the nose and mouth through a breathing mask (Hans Rudolph, USA). The mask was connected to a bidirectional turbine with an optocoupler airflow reader. The air sample $(1 \mathrm{~mL} / \mathrm{s})$ was pulled out of the turbine through the Nafion Permapure ${ }^{\circledR}$ capillary tube (removing moisture without changing the gas concentration) to fast oxygen (zirconium) and carbon dioxide (infrared) analysers. The turbine was calibrated before every examinee. Continuous monitoring of ventilationmetabolic indicators was enabled on the computer screen after conversion of the analogue-digital signal. Ventilation-metabolic indicators can be monitored for each breath-by-breath cycle. The data must be filtered at 30-second time intervals due to a large amount of data, and the highest values are taken as the maximum value of the indicator in a 30-second interval [21]. The test protocol began with an examinee being maximally relaxed at the place and breathing through the respiratory mask. After one minute, the examinee started to walk at $3 \mathrm{~km} / \mathrm{h}$ for 2 minutes. When a subject was walking on a treadmill, the speed was increased every minute by $1 \mathrm{~km} / \mathrm{h}$. At a speed of approximately $8 \mathrm{~km} / \mathrm{h}$, the examinee started to run (the start of the running speed was individual) and continued to run until he was no longer able to track the speed of the treadmill or had limiting factors or contraindications for early interruption of the test. The incline was constant at $1.5 \%$.

The second part of testing was conducted during official matches of the Croatian Premier Handball League. The official delegate of the Croatian Handball Referees Association gave evaluation of referees' performance during a match, which was later evaluated as the quality of refereeing with all grades in one season.

\section{VARIABLES SAMPLE}

Independent variables were the variables for determining the referees' functional abilities (Table 1). A rating of the referees' success at the end of the season, which is called in this study the quality of refereeing, is the criterion variable. The criterion variable is a grade which is evaluation of referees' performance during a match calculated from an internal refereeing report paradigm from the Croatian Handball Referees Association. The official supervisor who attends matches, cooperates with referees and helps them manage the match due to longterm refereeing experience (a former referee in the highest level of competition) is the only competent person to evaluate referees. This evaluation will be called in the remainder of the article the quality of refereeing. The quality of refereeing is an average of all grades recorded by supervisors during one season, which is a sum of all grades during the season divided by the number of matches during the season.

$$
\text { Quality of refereeing }=\frac{\text { Sum of all grades in a season }}{\text { Number of matches in a season }}
$$


Table 1. List of variables with a short name and the measuring unit

\begin{tabular}{|c|c|c|}
\hline Full variable name & Short name & $\begin{array}{l}\text { Measuring } \\
\text { unit }\end{array}$ \\
\hline Maximum oxygen uptake & $\mathrm{VO}_{2} \max$ & $\mathrm{I} / \mathrm{min}$ \\
\hline Relative maximum oxygen uptake & $\mathrm{RVO}_{2} \max$ & $\mathrm{ml} / \mathrm{min} / \mathrm{kg}$ \\
\hline Relative oxygen uptake at an anaerobic threshold & $\mathrm{RVO}_{2}$ max ant & $\mathrm{ml} / \mathrm{min} / \mathrm{kg}$ \\
\hline $\begin{array}{l}\text { Percentage of relative oxygen uptake at an anaerobic threshold of } \\
\text { maximum oxygen uptake }\end{array}$ & $\% \mathrm{RVO}_{2} \max$ ant & $\%$ \\
\hline Respiratory volume & VT & I \\
\hline Minute volume of breathing & VE max & $\mathrm{I} / \mathrm{min}$ \\
\hline Maximum heart rate & FS max & bpm \\
\hline Heart rate at an anaerobic threshold & FS ant & bpm \\
\hline $\begin{array}{l}\text { Percentage of the heart rate at an anaerobic threshold of the } \\
\text { maximum heart rate }\end{array}$ & $\%$ FS max ant & $\%$ \\
\hline Speed at an anaerobic threshold & v ant & $\mathrm{km} / \mathrm{h}$ \\
\hline Maximum treadmill speed & $v \max$ & $\mathrm{km} / \mathrm{h}$ \\
\hline
\end{tabular}

\section{DATA ANALYSIS}

Statistical software Statistica (ver. 13.4) was used for statistical analysis. Central and dispersion parameters, arithmetic mean (Mean) and standard deviations (SD) were calculated for all functional ability variables. Kolmogorov-Smirnov's test was performed to check the normality of distribution and the maximum deviation of the empirical and theoretical relative cumulative rate (Max D). Correlation of functional abilities (independent variables) and the quality of refereeing (dependent variable) was tested with a multiple regression analysis test, and the level of significance was set at $\mathrm{p}<0.05$.

\section{RESULTS}

The functional abilities of handball referees were measured by a spiroergometric test on a treadmill, and given the specificity of the variables and the measured indicators, each variable has its own measuring unit in which the result is expressed.

Table 2. Descriptive statistical parameters of functional abilities

\begin{tabular}{lcccccccc} 
N = 31 & MU & AM & MIN & MAX & SD & SKEW & KURT & MAX D \\
\hline VO2max & I/min & 4.08 & 3.12 & 4.74 & 0.42 & -0.40 & -0.54 & 0.09 \\
RVO2max & $\mathrm{ml} / \mathrm{min} / \mathrm{kg}$ & 45.35 & 38.06 & 61.02 & 6.12 & 1.10 & 0.91 & 0.14 \\
RVO2 max ant & $\mathrm{ml} / \mathrm{min} / \mathrm{kg}$ & 41.06 & 32.62 & 52.74 & 4.91 & 0.60 & 0.18 & 0.09 \\
\%RVO2max ant & $\%$ & 90.78 & 82.17 & 100 & 4.38 & 0.22 & -0.14 & 0.10 \\
VT & $\mathrm{I}$ & 3.06 & 2.32 & 4.23 & 0.46 & 0.62 & 0.08 & 0.10 \\
VE max & $\mathrm{I} / \mathrm{min}$ & 142.84 & 116 & 193.3 & 20.47 & 0.72 & 0.10 & 0.10 \\
FS max & $\mathrm{bpm}$ & 187.34 & 171 & 203 & 8.93 & -0.11 & -0.62 & 0.07 \\
FS ant & $\mathrm{bpm}$ & 176.51 & 161 & 191 & 8.51 & -0.12 & -0.59 & 0.11 \\
\%FS max ant & $\%$ & 94.26 & 86.01 & 98.84 & 2.93 & -1.32 & 2.87 & 0.17 \\
V ant & $\mathrm{km} / \mathrm{h}$ & 12.17 & 9 & 15 & 1.15 & -0.20 & 1.75 & 0.16 \\
V max & $\mathrm{km} / \mathrm{h}$ & 14.12 & 11.50 & 18 & 1.48 & 0.11 & 0.44 & 0.14 \\
\hline
\end{tabular}

Legend: $\mathrm{VO}_{2}$ max - absolute maximal oxygen uptake; $\mathrm{RVO}_{2} \max$ - relative maximal oxygen uptake; $\mathrm{RVO}_{2}$ max ant - relative maximal oxygen uptake at an anaerobic threshold; \%RVO2max ant - percentage of the relative maximal oxygen uptake at an anaerobic threshold; VT respiratory volume; VE max - maximum minute ventilation; FS max - maximum heart rate; FS ant - heart rate at an anaerobic threshold; \%FS max ant - percentage of the heart rate at an anaerobic threshold; $v$ ant - speed at an anaerobic threshold; $v$ max - maximum speed of treadmill; AS - arithmetic mean; MIN - minimal value; MAX - maximum value; SD - standard deviation; SKEW - skewness; KURT - kurtosis; MAX D - highest deviation of empirical and theoretical relative cumulative frequencies. 
All values of asymmetry and elongation indicate a normal distribution of results checked with Kolmogorov-Smirnov normality distribution test. Also, the same test indicates a lack of a statistically significant difference between the relative cumulative theoretical frequency and the relative cumulative empirical frequency (Table 3).

Table 3. Overview of regression analysis results for criterion variable quality of refereeing

\begin{tabular}{|c|c|c|c|c|c|c|}
\hline$N=31$ & Beta & $\begin{array}{l}\text { Std. Err. } \\
\text { of B }\end{array}$ & B & $\begin{array}{l}\text { Std.Err. } \\
\text { of B }\end{array}$ & $\mathrm{t}(21)$ & p-level \\
\hline Intercept & & & -672 & 1116 & -0.60 & 0.56 \\
\hline $\mathrm{VO}_{2} \max$ & 0.02 & 0.31 & 0 & 3 & 0.08 & 0.94 \\
\hline $\mathrm{RVO}_{2} \max$ & -0.66 & 3.83 & -0 & 2 & -0.17 & 0.86 \\
\hline $\mathrm{RVO}_{2}$ max ant & 0.48 & 3.52 & 0 & 3 & 0.14 & 0.89 \\
\hline$\% \mathrm{RVO}_{2} \max$ ant & -0.14 & 1.37 & -0 & 1 & -0.10 & 0.92 \\
\hline VT & 0.34 & 0.24 & 3 & 2 & 1.46 & 0.16 \\
\hline VE max & 0.24 & 0.25 & 0 & 0 & 0.97 & 0.35 \\
\hline FS max & 8.89 & 13.94 & 4 & 6 & 0.64 & 0.53 \\
\hline FS ant & -9.28 & 14.04 & -4 & 6 & -0.66 & 0.52 \\
\hline$\% F S$ max ant & 5.99 & 8.92 & 8 & 12 & 0.67 & 0.51 \\
\hline$v$ ant & -0.07 & 0.50 & -0 & 2 & -0.14 & 0.89 \\
\hline$v \max$ & 0.48 & 0.53 & 1 & 1 & 0.90 & 0.38 \\
\hline
\end{tabular}

Legend: $\mathrm{VO}_{2} \max$ - absolute maximal oxygen uptake; $\mathrm{RVO}_{2} \mathrm{max}$ - relative maximal oxygen uptake; RVO2 max ant - relative maximal oxygen uptake at an anaerobic threshold; \% $\mathrm{RVO}_{2} \max$ ant - percentage of the relative maximal oxygen uptake at an anaerobic threshold; VT - respiratory volume; VE max - maximum minute ventilation; FS max - maximum heart rate; FS ant - heart rate at an anaerobic threshold; \%FS max ant - percentage of the heart rate at an anaerobic threshold; $\mathrm{v}$ ant - speed at an anaerobic threshold; v max - maximum speed of treadmill; AS - arithmetic mean; MIN - minimal value; MAX - maximum value; SD - standard deviation; SKEW - skewness; KURT - kurtosis; MAX D - highest deviation of empirical and theoretical relative cumulative frequencies.

Using multiple regression analysis for the dependent variable of the quality of refereeing and selected functional abilities variables as independent variables standarized regression coeffcient were obtained with coefficients of significance.

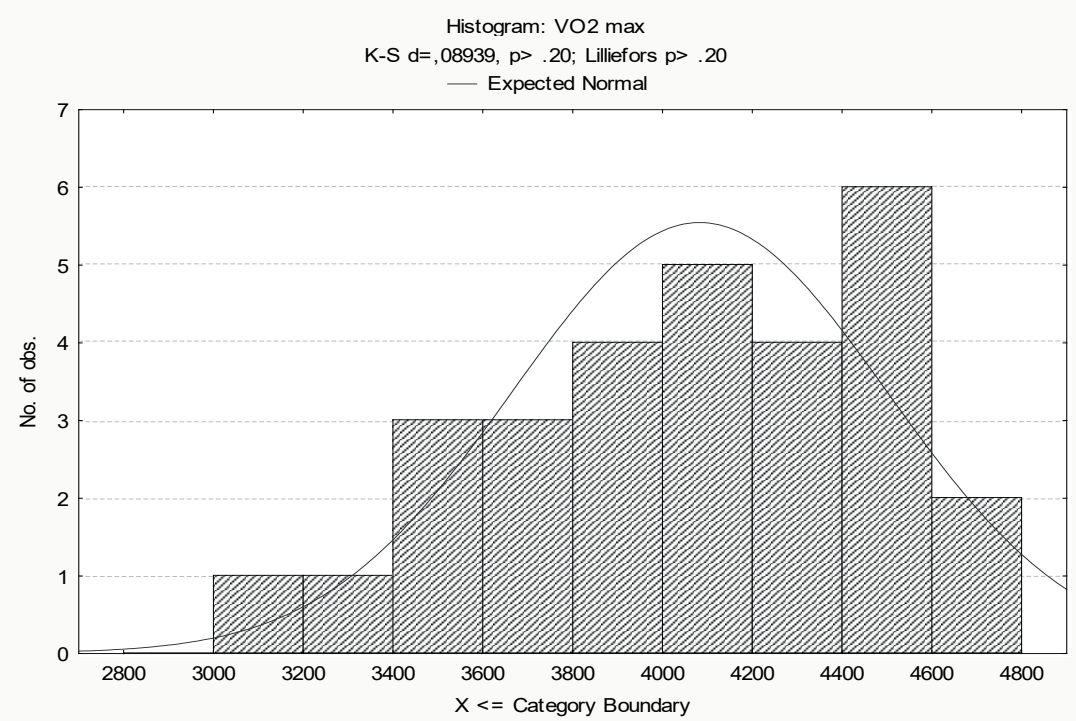

Fig. 1. Distribution of average results in $\mathrm{VO}_{2} \max$ - absolute maximal oxygen uptake 


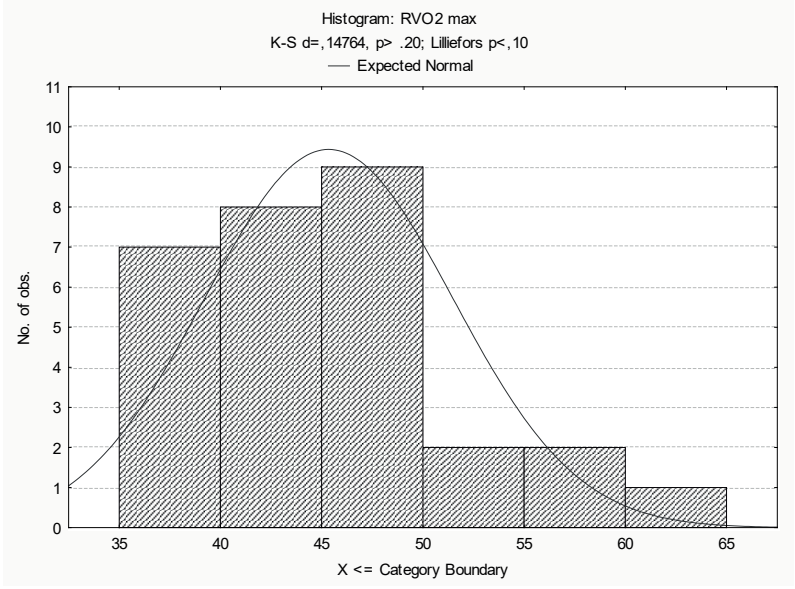

Fig. 2. Distribution of average results in $\mathrm{RVO}_{2} \mathrm{max}$ - relative maximal oxygen uptake

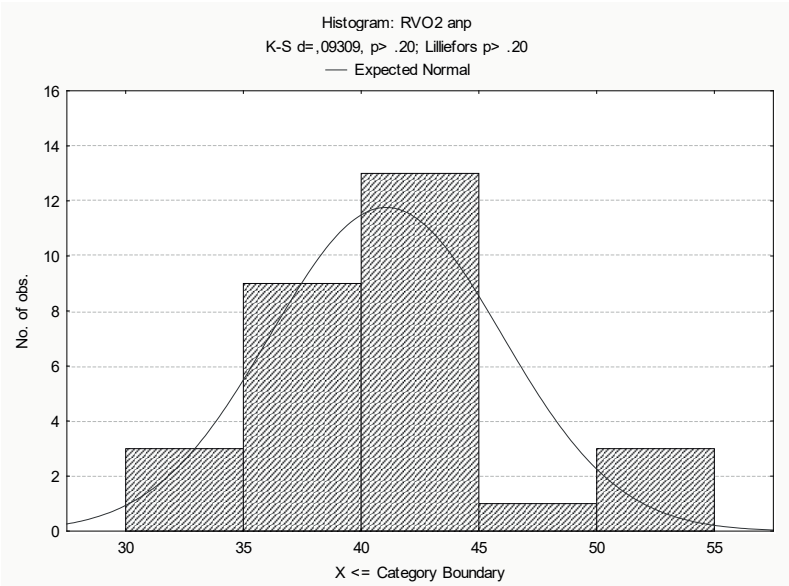

Fig. 3. Distribution of average results in $\mathrm{RVO}_{2}$ max ant - relative maximal oxygen uptake at an anaerobic threshold

\section{DISCUSSION}

Referees are engaged in physical activity from one to eight times a week (not counting matches which they officiate as physical activity). It is ungrateful to compare the obtained data with the population of handball players who train daily or more times a day, as most referees train only twice a week. The most relevant data for comparison is research of physiological loads of handball referees during a match [17]. In recent research of functional abilities of referees in more sports, the most widespread and commonly used data are related to relative maximum oxygen uptake, maximum speed, maximum heart rate, and speed and heart rate at an anaerobic ventilation threshold.

In the spiroergometric test on treadmill, the average maximum oxygen uptake of the examinees was $4.08 \pm 0.42 \mathrm{l} / \mathrm{min}$, while the average relative maximum oxygen uptake was $45.35 \pm 6.12 \mathrm{ml} / \mathrm{min} / \mathrm{kg}$. Considering the obtained data and comparing them with normative values of the relative maximum oxygen uptake 
was $45.35 \pm 6.12 \mathrm{ml} / \mathrm{min} / \mathrm{kg}$. Considering the obtained data and comparing them with normative values of the relative maximum oxygen uptake and considering the examinees' age, it can be concluded that referees have an average score for the general population and below an average one for the athletes' population. Considering that during the match the loads of the referees are sometimes equal or even higher than athletes' loads during matches [20], referees should increase their level of functional abilities through training. With better physical condition, they could easily follow all the requirements of the game, as bad physical preparation would not influence their decisions, i.e. the quality of refereeing. The referee must be physically fit to handle the toughest physical requirements throughout the game, and the physical preparation of a referee should not be a limiting factor in the quality of refereeing. Although in some leagues a lack of physical preparation can be compensated by experience, it is no longer possible at an international level and in higher leagues [15]. Recognizing the evolution of the handball game, this form of compensation will no longer be possible in the lower tiers of competitions in the near future.

In other studies of functional abilities, in particular with relative maximum oxygen uptake similar average results were obtained in the only published study of physiological loading by handball referees [17], which reported a figure of $48.5 \pm 6.1 \mathrm{ml} / \mathrm{kg} / \mathrm{min}$, which is only slightly higher, unlike basketball referees having a much better value of relative maximum oxygen uptake of $52.49 \pm 5.80 \mathrm{ml} / \mathrm{kg} / \mathrm{min}$ [22]. Research on football and rugby referees was also carried out, and the results of relative maximum oxygen uptake were obtained. Given the higher difference in the size of the playing ground and surface, the structural and functional analysis of activities between sports, it is understandable that football referees have better physical fitness and have better indicators of functional abilities. The relative maximum oxygen uptake values in football referees were $48.7 \pm 4.3 \mathrm{ml} / \mathrm{kg} / \mathrm{min}$ [23], $48.29 \pm 3.80 \mathrm{ml} /$ $\mathrm{kg} / \mathrm{min}$ [24] and $49.30 \pm 8.0 \mathrm{ml} / \mathrm{kg} / \mathrm{min}$ [8]. In the research of football referees [20], values of $59.94 \pm 7.09 \mathrm{ml} / \mathrm{kg} / \mathrm{min}$ and in the research of rugby referees [25], values of $59.8 \pm 5.8 \mathrm{ml} / \mathrm{kg} / \mathrm{min}$ are in line with results achieved by top athletes. Data on the average relative maximum oxygen uptake at an anaerobic ventilation threshold of $41.06 \pm 4.91 \mathrm{ml} / \mathrm{kg} / \mathrm{min}$, expressed in percentage with a relative maximum oxygen uptake of $90.78 \%$, indicate less developed anaerobic capacity of handball referees, respectively the ability to resist tiredness in dynamic activities of submaximal or maximal intensity under hypoxia or oxygen deficiency.

This is a reason why handball referees very quickly stopped with the spiroergometric test after passing an anaerobic ventilation threshold (they did not tolerate an increased lactate concentration), i.e. they reached their maximum. It has been noted that some referees had extremely poor lactate tolerance because as soon as they passed their anaerobic ventilation threshold, they could not continue testing and showed high grades on the scale of subjective loads feeling, and then they quit the test. The results point to the need for programmed anaerobic training to increase anaerobic capacity, so referees can maintain their quality of refereeing in parts of the game when the physiological loads are above their individual anaerobic thresholds. With better anaerobic capacity, referees would later pass the anaerobic threshold, i.e. they would pass it over higher percentage of the maximum oxygen uptake and the maximum heart rate. Given that referees' abilities (which influences the quality of refereeing) in increased blood lactate concentrations are lower, a higher level of physical preparation is required to prevent or reduce the time spent in that load zone 
for the purpose of better quality of refereeing. The average maximum heart rate during the spiroergometric test on the treadmill was $187.34 \pm 8.93$ beats per minute. Similar figures were published with other authors [26], where they recorded the average maximum heart rate by football referees with 190.5 \pm 7.9 beats per minute. Basketball referees [22] had $187.12 \pm 8.75$ beats per minute, which is almost the same as in this research. In previous studies, many authors used widely spread equation of 220 - years $=$ the maximum heart rate of the examinees. This is not true in practice [27] and, according to the data from this research, it is accurate in several cases, so it can be considered as accidentally given exact result. For scientific research in top sports, scientists should use one of the standardized procedures for measuring the maximum heart rate, such as in this research.

In handball referees, the average heart rate at an anaerobic ventilation threshold is $176.51 \pm 8.51$ beats per minute or expressed in percentage at the maximum heart rate of $94.26 \pm 2.93$. This data shows that referees have well-developed aerobic capacity, and poorly developed anaerobic one, which is logical in view of the predominantly aerobic type of training in handball referees. Since most referees (almost all) have declared that they practice only aerobic training at a constant speed over a given time interval, this data is very worrying. Knowing the loads during the game, especially those occurring in areas above the anaerobic ventilation threshold, when the concentration is reduced and when certain functional abilities are declining due to increased blood lactate concentrations, referees can easily make a wrong decision. This is very bad because in handball one decision can decide the winner of the match or even of the competition.

Based on the results of the regression analysis and the coefficient of multiple correlation of 0.70 and the coefficient of significance $p$ less than 0.20 , it can be concluded that there is no statistically significant correlation between the functional abilities of referees with quality of refereeing (Table 3). The determination coefficient of 0.49 indicates that a whole set of independent functional abilities variables share $49 \%$ of common variance. According to standardized regression coefficients in some variables for functional abilities, it can be concluded that functional abilities do not have a statistically significant effect on the quality of refereeing. This should be taken with a dose of caution, as the selected sample of referees are a group of top-level Croatian handball referees by the rankings at the end of each season, and the elimination criteria on the tests that must be met at official seminars in the pre-season and mid-season. Elimination criteria which must be met is 9.5 level in the Beep test which is questionable, especially in modern, quick and demanding handball, and recommendation is to raise this by at least one level. Variance among referees is small due to the aforementioned selection, and it does not distinguish referees in the tested functional abilities. If referees from other competition levels would be tested in this sample, there would be higher variability among referees and a higher possibility to confirm the hypothesis. With this data, it could be possibly concluded that the quality of refereeing would depend on referees' physical fitness and, consequently, well-developed functional abilities.

It has been noted that all supervisors of referees' performances (regardless of sports) give maximum marks for physical fitness (one of the rating subgroups that make the overall score) to referees and concentrate on other things they supervise during the match [20]. The supervisors do this because they believe 
that referees are physically fit for game requirements when passing elimination physical fitness tests at the beginning of the season during official seminar sessions. This practice is extremely bad and unacceptable in the context of the overall quality of refereeing. Particularly concerning is the detailed insight into the spiroergometric test results of handball referees, which shows inadequately developed functional abilities. Supervisors should pay more attention to this component of refereeing because it is known that poor physical preparation negatively affects the quality of refereeing [8, 9, 11, 12, 13, 20, 28]. This especially refers to decisions which are made in a very short time [9] and which can decide the match winner, or even in the worst case - the winner of the competition $[23,29,30,31]$.

\section{CONCLUSIONS}

The obtained results suggest that there is no statistically significant correlation between the tested functional abilities and the quality of refereeing, but this should be concluded very carefully and considering all indicators. Multiple regression analysis showed that no variables of functional abilities, or functional abilities as a whole, have obtained statistically significant correlation with the quality of refereeing, so we reject the hypothesis and conclude that there is no statistically significant correlation between better functional abilities and a better quality of refereeing.

Referees have a lower anaerobic capacity resulting from only aerobic exercise during individual preparation. Aerobic capacity is satisfactory for a handball match where aerobic energy processes (intense and extensive aerobic zones) prevail. During matches at shorter time intervals, anaerobic energy processes occur, which is mainly characterized by a decrease in functional abilities as well as cognitive abilities which are significant for refereeing, such as attention, concentration, and decision making. In order to minimize the possibility of making errors resulting from these aspects of refereeing, referees should carry out programmed training to raise the level of functional abilities with an emphasis on increased anaerobic capacity under supervision or with expert guidance.

Referees are a homogeneous group which is selected by the rankings at the end of each season and the elimination criteria on the tests that must be met at official seminars in the pre-season and mid-season. Given the existing selection, variance among referees is small and does not distinguish referees in the tested functional abilities in a way that some are more successful in their quality of refereeing. If there were no elimination criteria at the official seminars, there would be greater variability among referees and it would be possible to confirm the hypothesis. Differences between referees could appear if the subjects were referees from lower leagues, and this would be a recommendation for further studies.

For the previously mentioned facts, it is concluded that the existing selection of referees is good and there is no high variability among them, looking at their functional abilities. If the referees did not have an adequate level of physical preparation, specific morphological characteristics, and high scores in the quality of refereeing, they would not be competent or qualified to be referee at the highest level. 


\section{REFERENCES}

[1] Bilge M. Game analysis of Olympic, World and European Championships in men's handball. J Human Kinet. 2012;35(1):109-118. https://doi.org/10.2478/v10078-012-0084-7

[2] Sevim Y, Bilge M. The comparison of the last Olympic, World and European Men Handball Championships and the current developments in World Handball. Res Yearbook. 2007;13(1):70-6.

[3] Krüger K, Pilat C, Uckert K, Frech T, Mooren FC. Physical performance profile of handball players is related to playing position and playing class. J Strength Condition Res. 2014;28(1):117-25. https:// doi.org/10.1519/JSC.0b013e318291b713

[4] Belcic I, Marosevic A, Sukreski M. Differences in physiological loads and energy consumption of handball referees between periods in handball match. In: Skegro D, Belcic I, Sporis G, Krsticevic T, editors. Proceedings of World Congress of Performance Analysis in Sport XII; 2018 Sep 19-23; Opatija, Croatia. Zagreb: Faculty of Kinesiology; 2018, 357-63.

[5] Sporis G, Vucetic V, Milanovic L, Milanovic, Z, Krespi M, Krakan I. Anaerobic endurance capacity in elite soccer, handball and basketball players. Kinesiology. 2014;46:52-8.

[6] Povoas SCA, Ascensao AAMR, Magalhaes J, et al. Physiological demands of elite team handball with special reference to playing position. J Strength Condition Res. 2014;28(2):430-42. https://doi. org/10.1519/JSC.0b013e3182a953b1

[7] Matkovic B, Nedic A. Anthropological profile of soccer referees. Croatian Spors Med J. 2012;27:61-71.

[8] Castagna C, Abt G, D'Ottavio S. Activity profile of international-level soccer referees during competitive matches. J Strength Condition Res. 2004;18(3):486-496. https://doi.org/10.1519/15334287(2004)18<486:APOISR>2.0.CO;2

[9] Reilly T, Gregson W. Special populations: The referee and assistant referee. J Sport Sci. 2006;24(7):795801. https://doi.org/10.1080/02640410500483089

[10] Weston M, Castagna C, Impellizzeri F, Rampinini E, Abt G. Analysis of physical match performance in English Premier League soccer referees with particular reference to first half and player work rates. J Sci Med Sport 2007;10(6):390-7. https://doi.org/10.1016/j.jsams.2006.09.001

[11] Rebelo A, Ascensão A, Magalhães J, Bischoff R, Bendiksen, M, Krustrup P. Elite futsal refereeing: Activity profile and physiological demands. J Strength Condition Res. 2011;25(4):980-87. https://doi. org/10.1519/JSC.0b013e3181a392ed

[12] Valdevit Z, Ilic, D, Veskovic A, Suzovic D. The psychological features of team handball referees. Res Kinesiol. 2011;39:61-6.

[13] Weston M, Castagna C, Impellizzeri FM, Rampinini E, Breivik S. Ageing and physical match performance in English Premier League soccer referees. J Sci Med Sport 2010;13:96-100. https:// doi.org/10.1016/j.jsams.2008.07.009

[14] Belcic I, Sporis G. Differences between parameters of situational efficiency according to level of competition in Croatian handball leagues (case study). Acta Kinesiologica. 2012;6:39-44.

[15] Gruss K. The shuttle run - An endurance test for hockey referees. [Available at http://www.deutscherhockey-bund.de/VVI-web/Schiedsrichter/Ausbildung/sruntest.pdf] [Accessed on 10 May, 2020].

[16] MacMahon C, Helsen W, Starkes J, Weston M. Decision-making skills and deliberate practice in elite association football referees. J Sport Sci. 2007;25(1):65-78. https://doi.org/10.1080/02640410600718640

[17] Fernandes da Silva J, Castagna C, Carminatti L, Foza V, Guglielmo L, de Oliveira F. Physiological demands of team-handball referees during games. J Strength Condition Res. 2010;24(7):1960-2. https://doi.org/10.1519/JSC.0b013e3181ddb019

[18] Mallo J, Frutos P, Juárez D, Navarro E. Effect of positioning on the accuracy of decision making of association football top-class referees and assistant referees during competitive matches. J Sport Sci. 2012;30(13):1437-45. https://doi.org/10.1080/02640414.2012.711485

[19] Nabli MA, Abdelkrim NB, Castagna C, Jabri I, Batikh T, Chamari T. Physical and physiological demands of U-19 basketball refereeing: Aerobic and anaerobic demands. Physician Sportsmed. 2016;44(2):15863. https://doi.org/10.1080/00913847.2016.1149424

[20] Mazaheri R, Halabchi F, Seif Barghi T, Mansournia M. Cardiorespiratory Fitness and Body Composition of Soccer Referees; Do These Correlate With Proper Performance? Asian J Sport Med. 2016;7(1). https://doi.org/10.5812/asjsm.29577

[21] Vucetic V. Differences in runners' energy capacity indicators obtained by different load protocols [dissertation]. Zagreb: Faculty of Kinesiology; 2007.

[22] Rupcic T. Physiological loads of referees during basketball match [dissertation]. Zagreb: Faculty of Kinesiology; 2010.

[23] Caballero J, Ojeda E, Garcia-Aranda J, Mallo D, Helsen W, Sarmiento S, Veldivielso MN GarciaManso JM. Physiological profile of national-level Spanish soccer referees. Int Sportmed J Fims. 2011;2(2):85-91.

[24] Birinci M, Yılmaz A, Erkin A, Sahbaz S, Aydın I. Determination of relationship between respiratory parameters and aerobic capacity of referees. Procedia - Soc Behav Sci. 2014;152:353-7. https://doi. org/10.1016/j.sbspro.2014.09.210

[25] O'Hara J, Brightmore A, Till K, Mitchell I, Cummings S, Cooke C. Evaluation of movement and physiological demands of rugby league referees using global positioning systems tracking. Int J Sport Med. 2013;34(09): 825-831. https://doi.org/10.1055/s-0033-1333694

[26] Paes M, Fernandez R. Evaluation of energy expenditure in forward and backward movements performed by soccer referees. Braz J Med Biol Res. 2016;49(5):74-84. https://doi.org/10.1590/1414$431 \times 20155061$ 
[27] Correa Mesa J, Cruz Martinez L, Correa Morales J, Rojas Valencia J. Maximum Heart Rate during exercise: Reliability of the 220-age and Tanaka formulas in healthy young people at a moderate altitude. Revista de la Facultad de Medicina. 2015;62(4),579-85. https://doi.org/10.15446/revfacmed. v62n4.44539

[28] Castillo D, Yanci J, Cámara J, Weston M. The influence of soccer match play on physiological and physical performance measures in soccer referees and assistant referees. J Sport Sci. 2015;34(6):55763. https://doi.org/10.1080/02640414.2015.1101646

[29] Estriga ML, Ferreira A, Santiago C. Live Exertion Evaluation in Elite Handball Referees. In: Turner R, editor. Proceedings of 2nd EHF Scientific Conference; 2013 Nov 22-23; Vienna, Austria. Vienna: EHF; 2013, 46-9.

[30] Pizzera A, RaabM. Perceptual judgments of sports officials are influenced by the motor and visual experience. J Appl Sport Psychol. 2012;24(1):59-72. https://doi.org/10.1080/10413200.2011.608412

[31] Nazarudim NM, Abdullah MR, Suppiah PK, Fauzee MSO, Parnabas V, Abdullah NM. Decision making and performance of Malaysian rugby sevens referees. Movement, Health \& Exercise 2015;4(1):6175. https://doi.org/10.15282/mohe.v4i0.45 